\title{
UPRAVLJANJE KVALITETOM
} NEPROFITNIH ORGANIZACIJA U FUNKCIJI POBOLJŠANJA KONKURENTSKE PREDNOSTI

\section{QUALITY MANAGEMENT OF NON-PROFIT ORGANIZATIONS AT AIM TO IMPROVE COMPETITIVE ADVANTAGE}

\author{
Milka Ivanović \\ Beogradska poslovna škola - Visoka škola strukovnih studija, Beograd, Srbija \\ Zorana Antić \\ Beogradska poslovna škola - Visoka škola strukovnih studija, Beograd, Srbija
}

\section{() MESTE NGO}

JEL category: L3, L8, L84, M11, 014

\begin{abstract}
Apstrakt
Razvijanje, primena $i$ efektivno upravljanje kvalitetom u neprofitnim organizacijama značajno je ne samo sa aspekta poboljšanja usluga korisnicima, već i sa aspekta poboljšavanja efikasnosti i nivoa performansi, a sa ciljem postizanja konkurentnosti i pristupa fondovima. Polazeći od takve tvrdnje autori su istraživali primenu standarda kvaliteta u neprofitnim organizacijama zemalja u tranziciji sa akcentom na Srbiju i ustanovili da je jedan broj neprofitnih organizacija u zemljama u tranziciji primenio neki od koncepata upravljanja kvalitetom kao sredstvo za uspostavljanje kulture kvaliteta $i$ obezbeđenje dugoročnih ciljeva vezanih za satisfakciju korisnika i za osiguravanje izvora finansiranja. Međutim, ovakva praksa je, nažalost, redak primer u neprofitnim organizacijama u Srbiji, što umanjuje njihovu efikasnost $i$ efektivnost. Imajući takva saznanja i brojne poteškoće sa kojima se susreću neprofitne organizacije u Srbiji, kao i lošije rezultate postignute u pojedinim oblastima, nameće se potreba za standardizacijom poslovanja koja podrazumeva kreiranje i implementaciju efikasnog sistema menadžmenta kvalitetom. Stoga je cilj autora ovoga rada da ukažu na nužnost promene poslovnog ponašanja u smislu standardizacije poslovanja i u tom kontekstu podsticanje neprofitnih organizacija u Srbiji da primene neki od procesnih modela sistema kvaliteta.
\end{abstract}

Adresa autora zaduženog za korespodenciju:

Milka Ivanović

奉= milka.ivanovic@bbs.edu.rs
Ključne reči:

efektivno upravljanje kvalitetom, neprofitne organizacije, konkurentska prednost, standardizacija, performanse 


\begin{abstract}
Developed, implemented and effective quality management in nonprofit organizations is important not only in terms of improving customer service, but also in terms of improving the efficiency and performance levels, with the aim of achieving competitiveness and access to funds. Starting with these claims, the authors have investigated the use of quality standards in non-profit organizations in transition countries, focusing on Serbia. The results have shown that a number of nonprofit organizations in the countries in transition was applied by some of the concepts of quality management as a means of establishing a quality culture and providing long-term goals related to satisfaction of the users, in order to ensure the funding sources. However, this practice is, unfortunately, a rare example in non-profit organizations in Serbia, which reduces their efficiency and effectiveness. Having such knowledge and bearing in mind many difficulties faced by non-profit organizations in Serbia, as well as the poor results achieved in some areas, there is a need for standardization of business which includes the design and implementation of an effective quality management system. Therefore, the goal of the study is to point out the need for changes in business behavior, in terms of standardizing operations, encouraging non-profit organizations in Serbia to implement any of the process quality system model.
\end{abstract}

\title{
Keywords:
}

effective quality management, nonprofits, competitive advantage, standardization, performance

\section{UVOD}

Uslužni sektor beleži stalni rast u okviru globalne ekonomije, što nameće potrebu za detaljnijim izučavanjem i unapređenjem kvaliteta usluga (Ivanović \& Antić, 2011), u tom smislu se i od neprofitnih organizacija očekuje reinženjering (Schmidt, 2004) svih procesa i organizacionih paradigmi, koji baziraju na povećanoj efikasnosti i efektivnosti, što po mišljenju autora ovoga članka, nije moguće ostvariti bez efektivnog upravljanja kvalitetom. S druge strane, povećani su zahtevi u odnosu na obavezu i odgovornost neprofitnih organizacija da dokažu da njihovi programi doprinose pozitivnoj promeni u životima ljudi, za razliku od perioda s kraja prošloga veka, kada je prioritet bio samo praćenje rezultata i troškova (Poole, Davis, Reisman, \& Nelson, 2001). Nužnost usklađivanja sa promenama u okruženju nameće i potrebu opredeljivanja ka strategiji stvaranja što stabilnijeg i uspešnijeg dugoročnog razvoja (Forbes, 1998), pri čemu je realizacija i održavanje efektivne organizacije nužan preduslov, što je dodatni zahtev kada su u pitanju neprofitne organizacije. Saznanja bazirana na sekundarnim izvorima pokazuju da uspešna implementacija sistema menadžmenta kvalitetom (QMS) ima implikacija na sveukupno poslovanje (Baroniene, 2005), a da neprofitne organizacije dodatno čini fleksibilnijim i otvorenijim za inovacije. Takođe, na osnovu saznanja da TQM direktno utiče na poboljšanje performansi ((Easton \& Jarrell, 1998) (Hendricks \& Singhal, 1997) (Lemak, Reed, \& Satish, 1997) (Terziovski \& Samson, 1999) (Shetty, 1993) (Reed, Lemak, \& Mero, 2000)), sprovedeno je i primarno istraživanje na uzorku od 200 neprofitnih organizacija, koje posluju u oblasti obrazovanja, zdravstva, kulture, uključujući i NVO koje pokrivaju oblasti zaštite životne sredine, socijalna pitanja, zaštite ljudskih prava. Autori ovoga rada, apostrofirajući oblasti zdravstva i obrazovanja, zaključuju da se efektivna organizacija stvara, i konkurentska prednost generiše, najefikasnije preko QMS. QMS svojim organizacionim atributima upravljanja i kontrole, doprinosi kontinuiranom poboljšanju performansi neophodnih za postizanje efikasnosti i efektivnosti ((Anderson, Fornell, \& Lehmann, 1994); (Chapman, 2008)), a to znači preko razvoja kvaliteta i upravljanja kvalitetom. Ozbiljni zahtevi i očekivanja, s jedne strane, i potencijalne mogućnosti koje pruža efektivno upravljanje kvalitetom, s druge, uslovljavaju fleksibilnost i odgovornost neprofitnih organizacija, i u tom smislu, preispitivanje i prestrukturisanje poslovanja sa ciljem donošenja važnih menadžment odluka (Forbes, 1998) koje će im pomoći i u implementaciji filozofije kvaliteta (Ivanović, 2011) (Ivanović \& Antić, 2011), predstavlja prvi i značajan korak ka kreiranju kvalitetnih usluga. 


\section{ZNAČAJ EFEKTIVNOG UPRAVLJANJA KVALITETOM NA TRŽIŠTU NEPROFITNIH ORGANIZACIJA}

Globalizacija tržišta, izmenjeno privredno i industrijsko okruženje, nameće potrebu kontinuiranog usavršavanja i usklađivanja usluga sa svim elementima koji utiču na kreiranje potreba i zahteva korisnika. U takvim okolnostima eksplicite se nameće da je kvalitet važan činilac poslovnog uspeha na tržištu, koje je, neosporno, sve više orijentisano ka performansama kvaliteta, dok primena kvaliteta, kao modus poslovanja, vodi unapređenju efektivnosti i efikasnosti. Zbog toga, uspeh neprofitnih organizacija upravo zavisi od činjenice koliko efektivno i efikasno zadovoljavaju potrebe svojih korisnika (Kaplan, 2001), koliko su odgovorne prema njima, prema donatorima i vladinim izvorima finansiranja i kakvi su im organizacioni kapaciteti da isporuče efektivnu uslugu ((Eisinger, 2000) (Lam, 2004) prema (Cairns, et al., 2004) odnosno, koliko efektivno i etično koriste novac (Hoefer, 2000)).

lako sekundarna istraživanja pokazuju da su neki elementi kvaliteta prikazani kao kontroverzni, pri čemu, pojedini istraživači govore o teškoćama determinisanja kvaliteta u odnosu na uslugu, o konfuziji ((Crosby, 1979) u (Cronin \& Taylor, 1992)) šta treba da se meri, kvalitet usluge ili kvalitet života ((Walsh, 1995) (Osborne, 1996) prema (Cairns, Harris, Hutchison, \& Tricker, 2004)), a drugi istraživači imaju problem u tumačenju i predstavljanju kvaliteta ((Monroe \& Krishnan, 1983) u (Parasuraman, Zeithaml, \& Berry, 1985)), ipak tri osnovna principa kvaliteta: fokus na korisniku, timski rad i kontinualna poboljšanja ((Pegels, 1994); (Dean \& Bowen, 1994)), uz permanentnu kontrolu i ocenu kvaliteta, de facto predstavljaju ključne elemente za usklađivanje sa promenama na tržištu, stvarajući uslove za efektivnost i efikasnost, što značajno doprinosi poboljšavanju performansi i ostvarivanju konkurentnosti na tržištu.

S druge strane, kompleksnost ciljeva neprofitnih organizacija imanentna je složenom doživljaju kvaliteta, profilišući pažnju ka zadovoljstvu korisnika. Pored objektivnog doživljaja kvaliteta postoji i subjektivni koji veoma zavisi od ličnih odlika, uverenja i očekivanja, individualnih obrazaca sistema vrednosti Stoga je pitanje relacije kvalitetna usluga - zadovoljstvo korisnika veoma suptilno i delikatno i često zavisi samo od različitih pogleda korisnika i njihovog shvatanja kvaliteta (Evans \& Lindsey, 2010). Dobar primer za ilustraciju ove tvrdnje može se pronaći u zdravstvu, gde je percepcija pacijenata fokusirana na zdravstvenu uslugu, pri čemu je povećana osetljivost, a očekivanja ogromna. Sličan primer subjektivnog doživljaja kvaliteta može se pronaći i u obrazovanju, gde su očekivanja velika, a zadovoljstvo pruženom uslugom često vođeno subjektivnom percepcijom, individualnim očekivanjima i potrebama, koje su, ponekad i ispod nivoa standardizovanih kriterijuma, odnosno koje su fokusirane na krajnji rezultat - prolaznost na ispitu. Iz pomenutih razloga prepoznavanje značaja primene standarda kvaliteta i izbor adekvatnog modela i njegova pravilna primena, stvara prostor za eliminisanje konfuzije i za usklađivanje subjektivnog doživljaja kvaliteta sa stvarnim kvalitetom pruženih usluga.

Napred pomenuto dodatno potvrđuje i činjenica da tehnološki napredak uslovljava promene i unutar organizacija, menjajući njihovu organizacionu strukturu, potencirajući povećanu odgovornost svih zaposlenih i timski rad, pri čemu se primena principa menadžmenta kvalitetom može posmatrati kao strategijska odluka, posebno imajući u vidu jasno definisane zadatke i odgovornosti, kao i neprekidan proces evaluacije (ocenu, praćenje, osiguranje, održavanje i unapređenje) kvaliteta programa i usluga (Ivanović \& Antić, 2011), a što je svakako nužan preduslov standardizacije poslovanja i dobra osnova za eliminisanje improvizacije, nestručnosti,nesistematičnosti i neodgovornog, ležernog ponašanja, koje je odražavalo mnoge, kako poslovne tako i neprofitne subjekte zemalja u tranziciji kojima pripada i Srbija. Pored toga, složena struktura neprofitnih organizacija (Ivanović, 2011), proizašla iz različitih ciljeva, kultura, brojnih stejkholdera (Campbell, 2002), poslovanje vođeno misijom, pa i specifičnosti proizašle iz toga, doprinose teškoćama u merenju performansi, čineći sistem merenja veoma senzitivnim pitanjem ((Paton, 2003) u (Cairns, et al., 2004)). Međutim, instrumenti koje nudi implementirani sistem menadžmenta kvalitetom olakšavaju taj problem. Upravo, kao 
mehanizam uređenosti, efektivno upravljanje kvalitetom se fokusira na odgovornost i poboljšanje rada u svim segmentima realizacije misije, obezbeđujući informacije i ocene prema unapred utvrđenim kriterijumima i postupcima ocenjivanja, što čini opravdanost implementacije nekog od modela kvaliteta u neprofitnom sektoru mnogo većom. Stoga, u okviru ovog izazovnog konteksta, mnoge neprofitne organizacije pokušavaju, ili su već primenile neki koncept upravljanja kvalitetom, kao sredstvo za uspostavljanje kulture kvaliteta i obezbeđenje dugoročnih ciljeva vezanih za satisfakciju korisnika i za osiguravanje izvora finansiranja, dok na drugoj strani, još uvek postoje neprofitne organizacije koje nisu orijentisane ka primeni kvaliteta, čime su smanjile mogućnost efikasnog upravljanja, ostvarivanja poboljšanih performansi i konkurentnosti.

\subsection{Izgradnja kulture kvaliteta - preduslov efektivnog upravljanja kvalitetom}

Na osnovu sekundarnog istraživanja vidljivo je da mnoge neprofitne organizacije teže da budu savesne u smislu pružanja kvalitetne usluge, ili kulturno i moralno osetljive i socijalno odgovorne, ali koliko u tome uspevaju zavisi od njihove suštinske opredeljenosti koja se može prepoznati u stvarnoj implementaciji kvaliteta i negovanju kulture kvaliteta (Ivanović, 2011). Pitanje izgradnje kulture kvaliteta posebno je važno za neprofitne organizacije, jer one imaju dodatnu odgovornost i treba da služe kao primer ostalim segmentima u društvu (Ivanović, 2011). U tom smislu, usklađivanje sistema kvaliteta sa organizacionim vrednostima i njihovom misijom veoma je značajno i predstavlja prvi korak prilikom usvajanja modela za definisanje i primenu sistema kvaliteta i za razvijanje kulture kvaliteta. Ovo potvrđuje i Lisai (2011), dodajući da prilikom odabira modela treba uvažavati misiju, stavove top menadžera i privrženost zaposlenih. Takođe, sekundarni izvori pokazuju da je dobar upravo onaj sistem kvaliteta koji se uklapa u misiju i organizacione vrednosti, a koji doprinosi i ispunjavanju zadatih ciljeva neprofitnih organizacija. Posebno izbor modela koji je senzitivan na organizacionu kulturu (Cairns, Harris, Hutchison, \& Tricker, 2004) doprinosi kreiranju kulture kvaliteta, pri čemu u tom procesu vitalni značaj predstavlja komunikacija, timski rad, korišćenje alata kvaliteta, unapređenje znanja i veština. Posvećenost rukovodstva pitanju implementacije kvaliteta presudna je, između ostalog i stoga što ono ima dvostruku ulogu u ovom procesu, i to člana tima opredeljenog za promenu i ulogu trenera koji podstiče zaposlene da prihvate aspekte standarda kvaliteta, da neguju kulturu kvaliteta, da bi efektivno upravljali kvalitetom, ostvarivali bolje performanse i unapređivali poslovanje. Hojl (Hoyle, 2007) često podseća da su zaposleni srž organizacije i da imaju znanje, iskustvo i veštine koje menadžment treba da prepozna i da iskoristi na najbolji mogući način. Stoga, komunikacija koja se ostvaruje između zaposlenih i menadžmenta predstavlja važan element u kreiranju i održanju svesti o značaju kvaliteta, o implementaciji sistema kvaliteta i negovanju kulture kvaliteta. Da bi se održala svest o kvalitetu, Juran i Grina (Juran \& Gryna, 1993) predlažu i stalno merenje kvaliteta, što učvršćuje ideju o kulturi kvaliteta, koju isti autori definišu kao model ljudskih navika, verovanja i ponašanja.

Preporuka neprofitnim organizacijama koje žele uspešno da realizuju svoju misiju i ciljeve kvaliteta, da ostvare optimalne uslove za efektivno upravljanje kvalitetom i bolje performanse koje obezbeđuju konkurentnost na tržištu, neobično važnu i za pristup fondovima, jeste da uvaže tri aspekta kvaliteta (Heleta, 1998). Da stalno unapređuju kvalitet svojih usluga, odnosno da permanentno razvijaju kulturu kvaliteta sa ciljem postizanja zadovoljstva korisnika, dugoročnog opstanka i većeg kvaliteta života.

\subsection{Perspektive i opravdanost primene standarda kvaliteta sa aspekta dostizanja konkurentnosti na tržištu}

Teza da organizaciona kultura, ponašanje zaposlenih, njihova privrženost i motivisanost (Powell, 1995), blisko korespondira sa konkurentskom prednošću, svoje uporište ima u sekundarnim istraživanjima. S druge strane, standardizacija poslovanja, permanentno poboljšavanje i unapređivanje usluga, posebno u značajno izmenjenom i sve zahtevnijem poslovnom ambijentu, takođe dovode do ostvarivanja konkurentnosti na tržištu. 
Težnja ka sticanju konkurentske prednosti omogućava performanse poslovanja koje su iznad prosečnih, tj. vodi do karakteristika izvrsnosti (exellence) dokazujući da je obezbeđenje visokog kvaliteta jedinstveni i pravi put ka efikasnosti, efektivnosti i uspešnosti. Benefiti sticanja konkurentske prednosti mogu se sagledati u sledećih šest karakteristika (Wheelwright, 1989, pp. 15-32):

1. Kompanije stvaraju vrednost za kupca, jer su vođene njihovim potrebama i željama;

2. Konkurentska prednost značajno doprinosi celokupnoj efektivnosti poslovanja;

3. Efikasna upotreba jedinstvenih resursa;

4. Mogućnost za dalja unapređenja;

5. Jedinstveni način poslovanja koji konkurencija teško može da kopira;

6. Deluje motivišuće i pruža jasnu viziju svim zaposlenima.

S obzirom da sve navedene karakteristike i benefiti proizilaze iz principa menadžmenta kvalitetom, autori zaključuju da kvalitet predstavlja važan činilac efektivnog upravljanja i ostvarivanja konkurentske prednosti. Da bi bile konkurentne na tržištu i dugoročno održive, neprofitne organizacije treba da, pored kontinuiranog unapređivanja svojih performansi, poboljšavaju i veštine za njihovo merenje (Forbes, 1998), u čemu im može pomoći pravilno implementirani sistem kvaliteta, koji omogućava vrednovanje svih performansi, a time i doprinosi njihovom poboljšavanju ((Juran, 1994), (Deming, 1982) (Benson, Saraph, \& Schroeder, 1991) u (Ivanović \& Antić, 2011)).

Koncept upravljanja kvalitetom kao menadžment filozofija i preduslov za efektivno upravljanje organizacijom, bazira na zbiru teoretskih principa koji zahtevaju mobilizaciju svih organizacionih resursa u cilju boljeg razumevanja stejkholdera i njihovih zahteva (Guillen \& Gonzales, 2001).

Značajno je istaći i to da neprofitne organizacije koje su implementirale neki od programa kvaliteta ističu sledeće benefite (Cairns, Harris, \& Hutchison, 2004): mogućnost uticaja na performanse i njihovo unapređenje, bolji odnos sa eksternim okruženjem, bolju reputaciju u okviru sektora i bolji odnos sa partnerskim organizacijama.

Stvaranje konkurentske prednosti koja bazira na implementaciji i unapređenju kvaliteta, dugoročno posmatrano otvara perspektive za dalji razvoj i efektivno upravljanje, kako kvalitetom, tako i organizacijom, i potencira njene snage i mogućnosti za unapređenje. Stoga, neprofitne organizacije, da bi bile respektabilne, treba da imaju za cilj osiguranje kvalitetne usluge i da pokažu da rade na osnovu visokih standarda. Ovaj zahtev treba shvatiti kao imperativ, upravo stoga što neprofitne organizacije treba da pokazuju mnogo viši stepen odgovornosti, kako prema osnivačima, donatorima, tako i prema zakonodavcu, poverenicima i javnosti. $U$ tom smislu je veoma važna promena organizacione kulture, gde se upravljanje kvalitetom sagledava kao polazište, smatraju Peters i Voterman u (Gonzales \& Guillen, 2002). Isti autori naglašavaju da je za postizanje izvrsnosti neophodna promena ponašanja i stavova zaposlenih. Ovo saznanje prema mišljenju autora ovoga članka predstavlja jednu od najvećih prepreka i prilikom implementacije sistema menadžmenta kvalitetom. Razmišljanja u tom pravcu vode nas do Bartleta i Gosala u (Gonzales \& Guillen, 2002) koji apostrofiraju ulogu lidera na putu ka primeni procesnih modela i efikasnom upravljanju kvalitetom.

S obzirom na pomenuto, autori konstatuju da su organizaciona kultura i podrška rukovodstva, izuzetno važni prediktori za uspešnu implementaciju standarda kvaliteta. U zavisnosti od modela organizacione kulture zavisi način prihvatanja promena u obavljanju poslovnih aktivnosti, kao i usvajanje novih, efektivnijih i efikasnijih praksi (Ivanović \& Antić, 2011). Podrška rukovodstva ogleda se, pre svega, u nastojanjima zaposlenih da prihvate i adaptiraju promene, a potom i u činjenici koliko rukovodstvo polaže na potrebu obaveštavanja zaposlenih o nivou učinjenog napretka u postizanju cilja. Sledeći prediktori značajni za uvođenje standarda kvaliteta odnose se na tehnologiju, uključenost i pristup fondovima. Treba istaći, dakle, i značaj ostalih vrednosti organizacija koje se ogledaju u posedovanju adekvatne tehnologije (znanje, veštine, tehnike, hardver i 
softver), ili u uključenosti i pristupu fondovima. Ukoliko nedostaju ovakvi parametri, organizacije će, takođe, imati poteškoća u kreiranju, implementaciji i evaluaciji svojih usluga ili rezultata, što smanjuje mogućnosti za efikasno upravljanje kvalitetom. Potrebno je naglasiti $i$ činjenicu da su različita iskustva u upravljanju kvalitetom i postignutom efikasnošću i efektivnošću povezana sa pravilnom implementacijom kvaliteta. Nedovoljna efikasnost i efektivnost, prema rezultatima brojnih istraživača posledica je, upravo, nepotpune primene ključeva kvaliteta ((Hackman \& Wageman, 1995) u (Douglas \& Judge, 2001)).

Polazeći od ovakvih saznanja koja se odnose na ostvarene benefite i moguća ograničenja u postupku primene standarda kvaliteta, a na osnovu sekundarnih istraživanja, možemo konstatovati da su u praksi već zastupljeni različiti modeli i pristupi u unapređenju kvaliteta neprofitnih organizacija.

Vodeća britanska nezavisna organizacija za podršku neprofitnim organizacijama, Charities Evaluation Services - CES (prema (CES, 2010) (CES, 2012)) u nastojanju da neprofitnim organizacijama olakša donošenje odluke pri opredeljivanju za najadekvatniji standard kvaliteta u okviru postojećih sistema, kao i u postizanju efektivnije evaluacije i kvaliteta, savetuje in da rešenje potraže u odgovorima na sledeća pitanja:

- $\quad$ U kojoj meri je ponuđeni sistem u skladu sa njenim poslovanjem?

- Da li je jednostavno integrisati ponuđeni sistem u postojeću poslovnu praksu?

- Koliko će sistem uticati na organizacionu kulturu i obratno?

- Koliko je sistem jednostavan ili komplikovan? Koliko odgovara organizaciji?

- Koliko angažovanje resursa zahteva implementacija sistema?

3 PROBLEMI IMPLEMENTACIJE I EFEKTIVNOG UPRAVLJANJA KVALITETOM U NEPROFITNIM ORGANIZACIJAMA ZEMALJA U TRANZICIJI

Odlike zemalja u tranziciji imaju svoje specifičnosti koje se odražavaju na sve segmente poslovanja. Njihov razvoj karakteriše i dinamiku prilagođavanja sveukupnim promenama koje se odvijaju na tržištu. $U$ tom kontekstu može se posmatrati i primena $i$ upravljanje kvalitetom. Primer Srbije predstavlja dobru ilustraciju. Analizirajući razvoj i pozicioniranje neprofitnih organizacija $\mathrm{i} u$ tom kontekstu primenu i upravljanje kvalitetom, dolazi se do saznanja da Srbija, s obzirom na veoma kompleksne probleme koji su prisutni više od dvadeset godina uz izrazite političke tenzije $i$ brojne sukobe, zaostaje i za nekim zemljama u tranziciji. Ovakva tvrdnja bazira na sekundarnim istraživanjima, pri čemu se primenom komparativnog metoda došlo do saznanja da su se evropske neprofitne organizacije u velikoj meri već opredelile za neki od standarda kvaliteta koji im omogućava unapređenje performansi i veću efektivnost (Poole, Davis, Reisman, \& Nelson, 2001). Takođe, istraživanja pokazuju da su se mnoge neprofitne organizacije iz okruženja, npr. u Hrvatskoj i Mađarskoj opredelile za britanski standard PQASSO koji je nakon prilagođavanja specifičnostima, adaptiran za primenu ((ECNL, 2009.) u (Ivanović \& Antić, 2011)) u Mađarskoj, na primer, pod nazivom MINTA, a u Hrvatskoj pod nazivom SOKNO (Sustav osiguranja kvalitete za neprofitne organizacije (Anon, 2008). Neprofitne organizacije iz ostalih zemalja iz okruženja, s obzirom na dosadašnja istraživanja, nisu prepoznale mogućnosti koje pruža ovaj standard i nisu ga implementirale.

Podsetimo da se važna odlika standarda PQASSO (2010) ogleda u činjenici koja omogućava da se pomoću samoevaluacije podstiče veća uključenost $i$ odgovornost svih $u$ organizaciji, pri čemu se u diskusijama mogu planirati promene i razvijati ideje o efikasnijem radu organizacije, što bi svakako doprinelo $i$ bržem razvoju neprofitnih organizacija $u$ onim zemaljama u tranziciji, koje još uvek nisu implementirale ovaj standard, poput Srbije.

Empirijsko istraživanje na uzorku od 200 neprofitnih organizacija obavljeno je u Srbiji (Ivanović, 2011). Predmet istraživanja bile su neprofitne organizacije koje posluju u oblasti obrazovanja, zdravstva, kulture, kao i NVO koje pokrivaju oblasti zaštite životne sredine, socijalna pitanja i zaštite ljudskih prava. Osnovni cilj sprovedenog empirijskog istraživanja bio je da se 
ustanovi njihov razvoj i pozicioniranje. U sklopu ciljeva koji su se ticali njihove tržišne opredeljenosti, efikasnosti $\mathrm{i}$ efektivnosti, bili su sadržani i oni koji definišu oblast kvaliteta $i$ njegovu primenu. Polazište za ovaj deo empirijskog istraživanja ogleda se u sledećim definisanim hipotezama.

Hipoteza broj 1: Efektivna organizacija se stvara i generiše konkurentsku prednost najefikasnije preko menadžmenta kvalitetom.

Hipoteza broj 2: Standardizacija poslovanja i izgradnja kulture kvaliteta doprinose boljim performansama, što vodi ka stvaranju dobre reputacije i konkurentnosti.

Metodom komparativne analize sekundarnog i empirijskog istraživanja ustanovljeno je da je u Srbiji ubrzaniji razvoj neprofitnih organizacija nastupio tek posle 2000 godine (Ivanović, 2011.) sa uspostavljanjem demokratije, što se može razumeti i u kontekstu sporijeg prilagođavanja neprofitnih organizacija sveukupnim promenama, pa i onima koje se tiču implementacije standarda kvaliteta. Empirijsko istraživanje pokazuje da je pitanje upravljanja kvalitetom marginalizovano, da je nedovoljno primenjivano $i$ da neprofitne organizacije u Srbiji nisu prepoznale mogućnost efikasnijeg i efektivnijeg poslovanja uz primenu alata kvaliteta i uz efektivno upravljanje kvalitetom. Ilustracija pomenute tvrdnje svakako jesu dobijeni rezultati koji govore da je svega $10 \%$ ispitivanih neprofitnih organizacija primenilo standarde kvaliteta, dok se $61 \%$ izjasnio da i ne razmišlja o tome (Ivanović \& Antić, 2011), kao što se može videti na Slici 1.

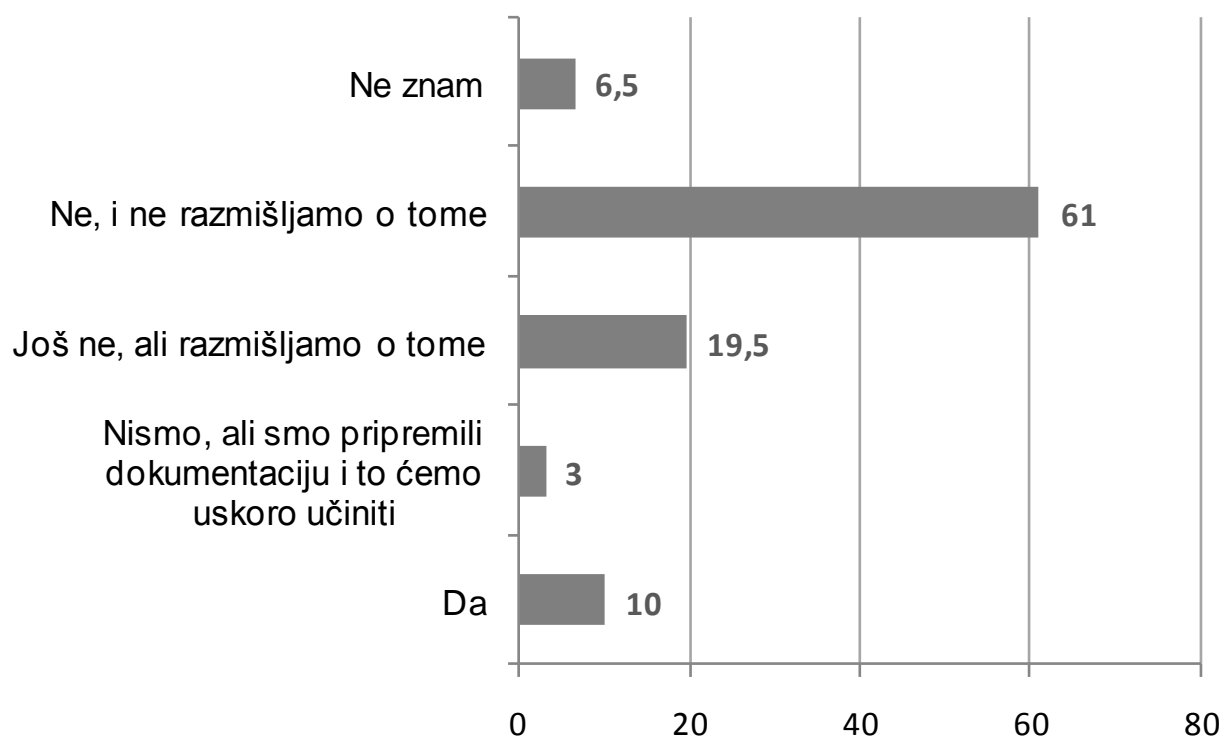

Slika 1 Implementacija sistema kvaliteta

S druge strane, postoji visoka svest o značaju kvaliteta i izgradnji kulture kvaliteta sa aspekta postizanja efikasnosti i efektivnog upravljanja. Kao što se može uočiti na Slici 2, ispitanici su na postavljeno pitanje visoko vrednovali (na skali od jedan do pet) primenu standarda kvaliteta i izgradnju kulture kvaliteta (4.74). (Videti: Sliku 2). Sledeća kategorija pitanja odnosila se na tržišnu opredeljenost neprofitnih organizacija. Opisujući svoje ciljeve i težnje da dostignu konkurentsku prednost na tržištu, anketirane organizacije su na izrečene tvrdnje uglavnom odgovarale pozitivno.
Najveći broj ispitanika navodi da se sve navedene tvrdnje barem delimično odnose na njih, čime su pokazali visoku svest o potrebi za stvaranjem konkurentske prednosti. Mogućnosti odgovora kretale su se od uopšte se ne slažem do $u$ potpunosti se slažem, a rezultati su prikazani u Tabeli 1 . Kao što se može uočiti, ispitanici su se izjasnili da veliku pažnju poklanjaju kvalitetu svojih usluga, pri čemu su visoko vrednovali tvrdnju da nastoje da se razlikuju od drugih upravo po kvalitetu svojih usluga (4.57). 


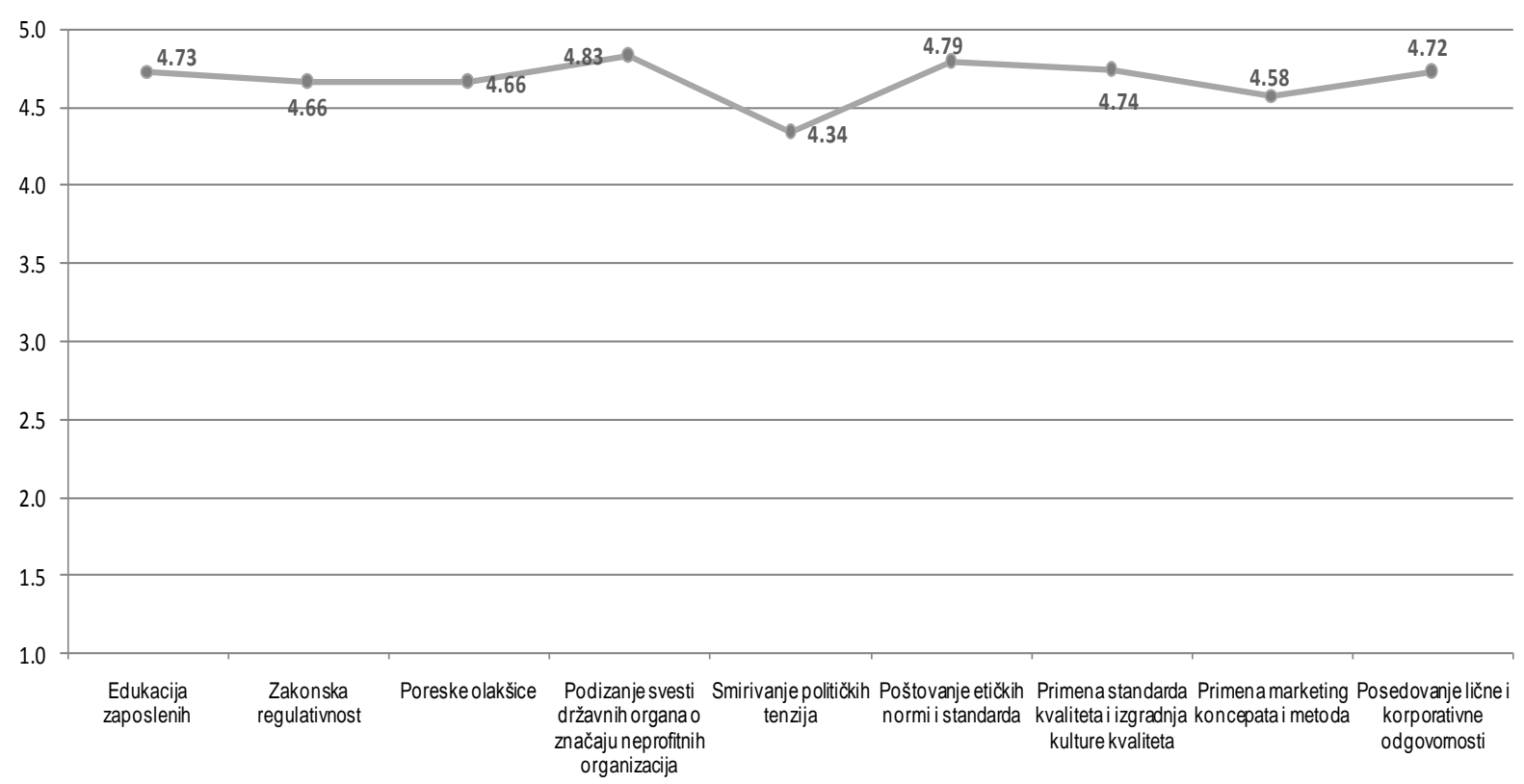

Slika 2 Faktori koji utiču na efektivno upravljanje

Poslednje pitanje u ovoj kategoriji odslikava stavove ispitanika o važnosti faktora za upravljanje i razvoj, pri čemu, ponovo većina ispitivanih neprofitnih organizacija visoko vrednuje sve faktore, jer se prosek odgovora kretao u rasponu od 4.54 - 4.75. Od deset ponuđenih faktora pitanje konstantnog poboljšanja kvaliteta ponovo je visoko vrednovano, jer je po stepenu važnosti stavljeno na četvrto mesto (4.67). Rezultati su vidljivi u Tabeli 2.

Postojeći nesklad u odgovorima i kontradiktornost, gde ispitanici u svim kategorijama visoko vrednuju primenu principa kvaliteta i izgradnju kulture kvaliteta, a da, pritom, sasvim mali broj njih stvarno primenjuje standarde kvaliteta, može se pronaći, po mišljenju autora, upravo u odlukama koje donosi vrhovni menadžment $\mathrm{i}$ da je to prava adresa na koju treba vršiti pritisak za odabir i primenu nekog procesnog modela, a sa ciljem postizanja veće efikasnosti i efektivnosti, koja se obezbeđuje efektivnim upravljanjem kvalitetom. $\mathrm{Na}$ taj način dostizanje konkurentske prednosti i u globalnim okvirima može biti cilj koji će se lakše i brže ostvariti.

Tabela 1 Tržišna opredeljenost i sticanje konkurentske prednosti

\begin{tabular}{|l|r|r|}
\hline & Prosek \\
\hline Osnovni cilj nam je zadovoljstvo korisnika & 4,74 \\
\hline Brzo reagujemo na promene i aktivnosti drugih organizacija & 4,13 \\
\hline Redovno prikupljamo informacije o aktivnostima ostalih organizacija & 4,09 \\
\hline Nastojimo da se razlikujemo od drugih po kvalitetu usluga & 4,57 \\
\hline Nastojimo da se razlikujemo od drugih po povećanoj odgovornosti prema korisnicima & 4,57 \\
\hline $\begin{array}{l}\text { Nastojimo da se razlikujemo od drugih po povećanoj odgovornosti prema društvenoj } \\
\text { zajednici }\end{array}$ & 4,47 \\
\hline $\begin{array}{l}\text { Nastojimo da se razlikujemo od drugih po povećanoj odgovornosti prema zaštiti životne } \\
\text { sredine }\end{array}$ & 4,09 \\
\hline
\end{tabular}


Ukoliko se uporede rezultati empirijskog istraživanja sa ostvarenim rezultatima $u$ pojedinim oblastima neprofitnih organizacija za 2011. god, a koji su prezentirani u medijima, može se uspostaviti bliska veza između neprimenjivanja standarda kvaliteta i ostvarivanja performansi. Konkretno, poslednji rezultati iz Brisela (maj, 2012.) gde su merene performanse (ishod lečenja, upotreba medikamenata, vreme čekanja na specijalističke preglede i operacije) zdravstvenih usluga u 34 zemlje Evrope, govore da Srbija zauzima poslednje mesto po kvalitetu svojih usluga ((EHCl, 2012) (Euro Health Consumer Index) - evropski zdravstveni potrošački indeks za 2012)). Oblast obrazovanja beleži pad kvaliteta usluga u domenu primene principa Bolonjske deklaracije i postizanja efikasnosti i efektivnosti. Ministri Evrope ocenili Srbiju ocenom 3.11, a četiri godine ranije imala je 3.8. (EHEA, 2012)

Tabela 2 Stavovi ispitanika o važnosti faktora za upravljanje i razvoj

\begin{tabular}{|l|c|}
\hline & Prosek \\
\hline Inovativnost i razvoj programa & 4.75 \\
\hline Veća finansijska ulaganja & 4.73 \\
\hline Profesionalizam & 4.72 \\
\hline Konstantno poboljšanje kvaliteta & 4.67 \\
\hline Permanentna edukacija kadrova & 4.65 \\
\hline Veća uključenost u društveni razvoj & 4.73 \\
\hline Razmena znanja & 4.67 \\
\hline Društveno odgovorno poslovanje & 4.58 \\
\hline Marketing pristup u radu & 4.54 \\
\hline Unapređenje poreskih olakšica & 4.57 \\
\hline
\end{tabular}

Problem efektivnosti i efikasnosti neprofitnih organizacija u Srbiji veoma je kompleksan. Kao jedan od uzroka lošijih poslovnih rezultata, može se pronaći u nedovoljnoj primenjivosti standarda kvaliteta i neblagovremenom usklađivanju sa promenama koje se odigravaju na globalnom tržištu. Jer, prošireno tržište zahteva brže i energičnije prilagođavanje novim zahtevima što dodatno obavezuje menadžment neprofitnih organizacija na donošenje pravilnih odluka, na usklađivanje sa savremenim trendovima i po pitanju implementacije standarda kvaliteta.

\section{ZAKLJUČAK}

Bazirajući svoje tvrdnje na rezultatima istraživanja, a koje se odnose na lošu implementaciju sistema kvaliteta, pri čemu se eliminišu uslove za efektivno upravljanje kvalitetom koje vodi ka konkurentskoj prednosti, autori procenjuju da je potrebno podsticati neprofitne organizacije u Srbiji da standardizuju svoje poslovanje odabirom modela kvaliteta koji je u skladu sa njihovom misijom i organizacionim vrednostima, kao garanta permanentnom unapređenju kvaliteta usluga, bez kojeg nije

Published: July 2013 moguće obezbediti efektivno upravljanje i konkurentnost na tržištu, a time ni bolju poziciju i dugoročnu održivost.

Sagledavajući ograničenja u implementaciji ideje kvaliteta $\mathrm{u}$ ispitivanim organizacijama, autori smatraju da pored neopredeljenosti i nedovoljnog angažovanja i požrtvovanosti nadređenih, dominiraju nedovoljna informisanost o raspoloživosti programa kvaliteta koje je moguće primeniti $u$ neprofitnom sektoru, neusklađenost programa kvaliteta sa organizacijom (njenom strukturom, misijom, vizijom, procesima, aktivnostima), a takođe, kao ograničenje može se navesti i nedovoljna posvećenost i angažovanje zaposlenih na polju kvaliteta. Otuda i težnja autora da se posebno utiče na viši nivo menadžmenta da svoje odluke usklađuje sa savremenim trendovima tržišta. Neprofitne organizacije, ukoliko žele da nastave u pravcu ispunjenja socijalnih ciljeva i doprinosa opštim društvenim kretanjima, neminovno moraju da preispitaju svoju suštinsku ulogu i da se okrenu novim, inovativnijim, odgovornijim i kvalitetnijim uslugama. Razlog više za ovakvu neminovnost 
jeste i kompleksni tržišni ambijent koji je sve zahtevniji. Fundamentalni okvir za tržišnu orijentaciju predstavlja kvalitativno poboljšanje usluga, a u tom pravcu primena tehnika i metoda iz domena sistema menadžmenta kvalitetom postavlja se kao imperativni zadatak. U prilog tome govori i činjenica da je efektivan i kvalitetan menadžment sistem dinamičan samo ukoliko je osposobljen da se adaptira i menja u skladu sa potrebama, zahtevima i očekivanjima potrošača/korisnika.

\section{Citirani radovi}

Anderson, E. W., Fornell, C., \& Lehmann, D. R. (1994). Customer satisfaction, market share, and profitability. Journal of marketing(53), 53-56.

Anon. (2008, 02 09). Sustav osiguranja kvalitete za neprofitne organizacije (SOKNO) Retrieved from Smart: http://www.smart.hr/index.php?option=com_content\&task=view\&id=37\&ltemid=1

Baroniene, L. (2005, 0630$)$. The Role of Quality Management in the process of Innovation Development. Engineering Economics, 43(3), 15-21.

Benson, P. G., Saraph, J. V., \& Schroeder, R. G. (1991). The effects of organizationalcontext on quality management: an empirical investigation. Management Science, 37(9), 1107-1124.

Cairns, B., Harris, M., \& Hutchison, R. (2004). A summary of the ACU's pilot studies of governanance support for small voluntary and community organisations, London: Home Office.

Cairns, B., Harris, M., Hutchison, R., \& Tricker, M. (2004). Improving Performance? The Adoption and Implementation of Quality Systems in UK Nonprofits. Birmingham, UK: Centre for Voluntary Action Research, Aston Business School.

Cairns, S., Sloman, L., Newson, C., Anable, J., Kirkbride, A., \& Goodwin, P. (2004). Smarter Choices - Changing the Way We Travel. Report for Department for Transport.

Campbell, D. (2002). Outcomes assessment and the paradox of nonprofit accountability. Nonprofit Management and Leadership, 12(3), 243-259. Retrieved from http://ucanr.org/sites/ceprogramevaluation/files/113732.pdf

CES. (2012, May). Charities Evaluation Services: at the forefront of third sector performance improvement. Retrieved from Charities Evaluation Services: http://www.ces-vol.org.uk/how-we-can-help/about-ces/allabout-CES

Chapman, A. (2008). Quality management - quality Management history, gurus, TQM theories, process improvement and organisational excellence. Retrieved 03 01, 2012, from businessballs: http://www.businessballs.com/qualitymanagement.htm

Cronin, J. J., \& Taylor, S. A. (1992, July). A reexamination and extention. Journal of Marketing, 56, 55-68.

Crosby, P. B. (1979). Quality is free: The art of making quality certain. New York: McGraw Hill Custom Publishing.

Dean, J. J., \& Bowen, D. (1994, 07). Management theory and total quality: Improving research and practice through theory development. The Academy of Management Review, 19(3 Special Issue: "Total Quality"), 392-18.

Deming, W. E. (1982). Out of the Crisis. Cambridge: Cambridge University Press.

Douglas, T., \& Judge, W. (2001). Total quality management implementation and competitive advantage: the role of structural control and exploration. Academy of Management Journal, 44(1), 158-169.

Easton, G., \& Jarrell, S. (1998). The effects of total quality management on corporate performance: An empirical investigation. Journal of Business, 71(2), 253-307.

EHCI. (2012). EHCl - Euro Health Consumer Index. Preuzeto sa http://svetmedicine.com/index.php.

EHEA. (2012). EHEA - ministarska konferencija. Retrieved from EurActive: www.euractiv.rs/eu-prioriteti

Eisinger, P. (2000). The politics of bread and circuses: building the city for the visitor class. Urban Affairs Review(35), 316-333.

Evans, J. R., \& Lindsey, W. M. (2010). The management and control of quality. USA: South-Western Pub/Thomson.

Forbes, D. (1998). Measuring the Unmeasurable: Empirical Studies of Nonprofit Organization Effectiveness from 1977 to 1997. Nonprofit and Voluntary Sector Quarterly, 27(2). Retrieved from http://nvs.sagepub.com/content/27/2/183.short

Gonzales, T. F., \& Guillen, M. (2002). Leadership Ethical dimension: a requirement in TQM implementation. The TQM Magazine, 14(3), 150-164. 
Guillen, M., \& Gonzales, T. (2001). The Ethical Dimension of Managerial Leadership: Two illustrative Case Studies in TQM. Journal of Business Ethics, 34(3-4), 175-189.

Hackman, J., \& Wageman, R. (1995). Total quality management: empirical, conceptual and practical implications. Administrative Science Quarterly, 40(2), 309-342.

Heleta, M. (1998). TQM model za poslovnu izvrsnost. Beograd: Educta.

Hendricks, K. B., \& Singhal, V. R. (1997, 09). Does Implementing an Effective TQM Program Actually Improve Operating Performance? Empirical Evidence from Firms that have Won Quality Awards . Management Science, 43(9), 1258-1274.

Hoefer, R. (2000). Accountability in Action? Program Evaluation in Nonprofit Human Services Agencies. Nonprofit Management and Leadership, 10(2), 167-177.

Hoyle, D. (2007). ISO 9000, Quality systems handbook. Butterworth-Heinemann.

Ivanović, M. (2011). Strategija društvenog marketinga u pozicioniranju neprofitnih organizacija (doktorska disertacija). Beograd: Fakultet organizacionih nauka.

Ivanović, M., \& Antić, Z. (2011). Vrednovanje poslovnih rezultata neprofitnih organizacija. Management-časopis za teoriju i praksu menadžmenta, vol.16, br 61, str. 99-1, 16(61), 99.

Juran, J. M. (1994). Managerial breakthrough. New York: McGraw-Hill.

Juran, J. M., \& Gryna, F. M. (1993). Planiranje i analize kvalitete. Zagreb: McGraw-Hill, Mate.

Kaplan, R. S. (2001, Spring). Strategic Performance Measurement and Management in Nonprofit Organisations. Nonprofit management \& Leadership, 11(3),, 353-370.

Lam, W. (2004). Technical Risk Management on Enterprise Integration Projects. Communications of the Association for Information Systems, 13, Article 20. Retrieved from http://aisel.aisnet.org/cais/vol13/iss1/20

Lemak, D. J., Reed, R. Y., \& Satish, P. K. (1997). Commitment to quality management: Is there a relationship with firm performance? Journal of quality management, 2(1), 67-86.

Lisai, D. (2011). Choosing and Implementing a Quality Management System at Statistics Sweden. Linkoeping: Linkoeping University, Sweden.

Monroe, K. B., \& Krishnan, R. (1983). The effect of priceon subjective product evaluations. working paper. Blackburg: Virginia Polytechnic Institute.

Osborne, S. (1996). Performance and quality management in VNPOs. London: in S. Osborne (ed.) Managing in the Voluntary Sector International Thomson Business Press.

Parasuraman, A., Zeithaml, V. A., \& Berry, L. L. (1985). A Conceptual Model of Service Quality and Its Implications for Future Research. Journal of Marketing.

Paton, R. (2003). Managing and measuring social enterprises. London: Sage Publications.

Pegels, C. (1994). Total quality management defined in terms of reported practice. International Journal of Quality and Reliability Management, 11(5), 6-18.

Poole, D. L., Davis, J. K., Reisman, J., \& Nelson, J. E. (2001). Improving the Quality of Outcome Evaluation Plans. Nonprofit Management \& Leadership, 11(4).

Powell, T. (1995). Total quality management as competitive advantage, A review and empirical study. Strategic Management Journal, 16, 15-37.

PQASSO. (2010). Achieving PQASSO quality mark. (Charities Evaluation Services) Retrieved from All Souls Clubhouse: http://www.clubhouse-qa.org.uk/policys/PQASSO\%20accreditation\%20proceedure.pdf

Reed, R., Lemak, D. J., \& Mero, N. P. (2000). Total quality management and sustainable competitive advantage. Journal of Quality Management(5), 5-26.

Schmidt, E. (2004). How Ethical Is Your Nonprofit Organization? Management Journal, 16(1), 15-37. Retrieved 02 02, 2013, from http://www2.guidestar.org/rxa/news/articles/2004/how-ethical-is-your-nonprofitorganization.aspx?articleld $=827$

Shetty, Y. K. (1993). Aiming high: competitive benchmarking for superior performance. Long Range Planing, 26(1), 39-44.

Terziovski, M., \& Samson, D. (1999). The link between total quality management practice and organisational performance. International Journal of Quality \& Reliability Management, Vol. 16 Iss: 3, pp., 226 - 237.

Walsh, J. P. (1995). Managerial and organizational cognition: Notes from a trip down memory lane. Organization Science, 280-321. Retrieved from http://jamespwalsh.com/Resources/Walsh\%20-\%201995\%20\%20Managerial\%20and\%20organizational\%20cognition\%20\%20Notes\%20from\%20a\%20trip\%20down\%20memory\%20lane.pdf

Wheelwright, S. C. (1989). Competing through manufacturing, International handbook of production and operation management. London: Cassel Educational, Ltd. 
Datum prve prijave:

Datum prijema korigovanog članka:

Datum prihvatanja članka:
03.02.2013.

26.03.2013.

09.04.2013.

\section{Kako citirati ovaj rad?}

Style-APA Sixth Edition:

Ivanović, M., \& Antić, Z. (2013, 07 15). Upravljanje kvalitetom neprofitnih organizacija u funkciji poboljšanja konkurentske prednosti. (Z. Čekerevac, Ed.) FBIM Transactions, 1(2), 73-84. doi:10.12709/fbim.01.01.02.08

Style - Chicago Fifteenth Edition:

Ivanović, Milka, and Zorana Antić. "Upravljanje kvalitetom neprofitnih organizacija u funkciji poboljšanja konkurentske prednosti." Edited by Zoran Čekerevac. FBIM Transactions (MESTE) 1, no. 2 (07 2013): 73-84.

Style- GOST Name Sort:

Ivanović Milka and Antić Zorana Upravljanje kvalitetom neprofitnih organizacija u funkciji poboljšanja konkurentske prednosti [Journal] = Upravljanje kvalitetom neprofitnih organizacija // FBIM Transactions / ed. Čekerevac Zoran. - Belgrade : MESTE, 07 15, 2013. - 2 : Vol. 1. - pp. 73-84. ISSN 2334-704X (Online); ISSN 2334-718X.

Style Harvard Anglia:

Ivanović, M. \& Antić, Z., 2013. Upravljanje kvalitetom neprofitnih organizacija u funkciji poboljšanja konkurentske prednosti. FBIM Transactions, 15 07, 1(2), pp. 73-84.

Style - ISO 690 - Numerical Reference:

Upravljanje kvalitetom neprofitnih organizacija u funkciji poboljšanja konkurentske prednosti.

Ivanović, Milka and Antić, Zorana. [ed.] Zoran Čekerevac. 2, Belgrade : MESTE, 07 15, 2013, FBIM Transactions, Vol. 1, pp. 73-84. ISSN 2334-704X (Online); ISSN 2334-718X. 